\title{
Clinical Study \\ Basal Cell Carcinoma in Asians: A Retrospective Analysis of Ten Patients
}

\author{
Michael G. Moore ${ }^{1}$ and Richard G. Bennett ${ }^{2}$ \\ ${ }^{1}$ School of Medicine, Indiana University, Indianapolis, IN 46202-3082, USA \\ ${ }^{2}$ School of Medicine, University of California at Los Angeles, Los Angeles, CA 90095, USA
}

Correspondence should be addressed to Michael G. Moore, mgmoore@gmail.com

Received 31 March 2012; Accepted 10 May 2012

Academic Editor: M. Lebwohl

Copyright ( $\odot 2012$ M. G. Moore and R. G. Bennett. This is an open access article distributed under the Creative Commons Attribution License, which permits unrestricted use, distribution, and reproduction in any medium, provided the original work is properly cited.

Background. Few studies have been done that characterize basal cell carcinoma (BCC) in Asians because this tumor is relatively uncommon in this population group. Objective. To characterize BCC in Asians. Methods. We retrospectively examined fifteen patient variables and eight tumor variables of ten Asian patients with BCC and compared these results to those of thirty matched Caucasian controls with BCC. Results. Asians developed their first BCC at an older age than the age of first BCC in Caucasian controls $(68.9$ years versus 58.3 years; $P<0.05$ ). During their lifetime, Asians had fewer BCCs than the number of BCCs in Caucasian controls $(1.11$ versus $5.41 ; P<0.02)$, despite a similar estimated lifetime daily sun exposure (hours/day) for both groups. Compared to BCCs in Caucasian controls, a higher percentage of BCCs in Asians were clinically pigmented (50.0\% versus $3.3 \% ; P<0.01)$. Conclusion. Asians develop BCCs later in life and develop fewer BCCs over their lifetime than Caucasians, despite similar estimated lifetime daily sun exposure. This finding is probably due to skin pigmentation in Asians being more protective of ultraviolet light than skin pigmentation in Caucasians.

\section{Background}

Basal cell carcinoma (BCC) is the most common skin cancer in Caucasians but is uncommon in Asians (referring to the non-Indian population originating in Asia) and Black African races [1-3]. Many reviews have been published that give a clinical overview of $\mathrm{BCC}$ and describe its incidence in light-skinned Caucasians [4-14]. Less attention has been paid, however, looking at BCC in nonwhite races such as Black Africans [2, 3, 15-18] and Asians [1, 3, 19-30]. Those studies that have been performed on Asians were primarily done in Japanese hospitals and consequently lacked a control population that allowed for direct comparison to other races $[1,20-23,27]$. Therefore, we analyzed patient and tumor variables in our Asian patients with BCC and compared these data with those in matched Caucasian controls.

\section{Patients and Methods}

Medical records of ten sequential Asian patients with BCC from the Mohs micrographic surgery practice of one of the authors (RGB) from January 1992 to January 2001 were identified. All patient records were deidentified prior to performing a retrospective review and consequently Institutional Review Board approval was not obtained.

We recorded for analysis fifteen patient variables and eight tumor variables from these patient charts. The fifteen patient variables included the following: ethnic background, gender, age of onset of first BCC, occurrence of multiple $(>1)$ lifetime BCCs, the number of lifetime BCCs, Fitzpatrick skin phototype, presence of fair skin, estimated average lifetime daily sun exposure (hours/day), chemical exposure history, excessive X-ray exposure history, smoking history (pack years), non-BCC skin cancer history, family skin cancer history, and personal and family history of other cancer. The eight tumor variables included the following: clinical pigmentation, duration prior to treatment, location, BCC subtype, number of Mohs stages required for removal, preoperative area (measured BCC size), postoperative area (measured postoperative wound size), and history of prior treatment. 
TABLE 1: Patient variables.

\begin{tabular}{|c|c|c|c|}
\hline Patient variables & Asians $(n=10)$ & Caucasian controls $(n=30)$ & $P$ value \\
\hline Mean age (years) of onset for first BCC & $68.9 \pm 13.2$ & $58.3 \pm 14.0$ & $<0.05$ \\
\hline Occurrence of multiple $(>1)$ lifetime BCC & $1(11.1 \%)^{*}$ & $23(79.3 \%)^{* *}$ & $<0.01$ \\
\hline Mean number of lifetime BCCs & $1.11 \pm 0.33^{*}$ & $5.41 \pm 5.03^{* * *}$ & $<0.02$ \\
\hline Mean Fitzpatrick skin phototype & $3.44 \pm 1.42^{*}$ & $2.72 \pm 1.16^{* *}$ & $<0.15$ \\
\hline Presence of fair skin & $2(20.0 \%)$ & $18(62.1 \%)^{* *}$ & $<0.04$ \\
\hline Mean sun exposure (hours/day) & 2.5 & 2.77 & $<0.70$ \\
\hline History of chemical exposure & $4(44.4 \%)^{*}$ & $7(24.1 \%)^{* *}$ & $<0.40$ \\
\hline History of X-ray exposure & $2(22.2 \%)^{*}$ & $11(31.0 \%)^{* *}$ & $<0.46$ \\
\hline Mean smoking pack years & $18.8 \pm 24.75$ & $10.3 \pm 18.0$ & $<0.45$ \\
\hline Hx of non-BCC skin cancer & $0(0 \%)$ & $5(17.2 \%)^{* *}$ & $<0.32$ \\
\hline FHx of skin cancer & $0(0 \%)$ & $10(33.3 \%)^{* *}$ & $<0.08$ \\
\hline Hx of other cancer & $0(0 \%)$ & $8(27.6 \%)^{* *}$ & $<0.16$ \\
\hline FHx of other cancer & $5(55.5 \%)^{*}$ & $21(69.9 \%)^{* *}$ & $<0.44$ \\
\hline
\end{tabular}

${ }^{*} n=9,{ }^{*} n=29$ due to unavailable data, and ${ }^{* * *} n=27$ due to unavailable data.

To compare the patient and tumor variables of our Asian patients with those in Caucasians, we chose, using a table of random numbers applied to the Mohs surgery log book, thirty Caucasian control patients matched for gender and year of treatment. We excluded from this study BCCs arising in association with sebaceous nevus of Jadassohn and patients who were immunocompromised or who had basal cell nevus syndrome or xeroderma pigmentosum.

A Fitzpatrick skin phototype (i-vi) was assigned to each patient based on their ability to tan and burn from sunlight. These phototypes were determined as follows: (i) burns easy, never tans; (ii) burns easy, tans minimally; (iii) burns sometimes, tans sometimes; (iv) burns minimally, tans well; (v) rarely burns, tans well; (vi) never burns, very dark skin [31]. Besides the Fitzpatrick skin phototype, the skin of each patient was classified as fair, medium, or dark.

The number of smoking pack years was calculated as follows: mean number of packs of cigarettes smoked per day multiplied by the number of years smoked.

$P$ values were calculated using the two-tailed Students $t$ test for comparison of means and the Fisher exact test for the comparison of percentages. Differences were considered statistically significant for $P \leq 0.05$.

\section{Results}

The ethnic backgrounds and genders of the ten Asian patients are as follows: five Japanese, one South Korean, one Philippino, one Philippino/German, one Chinese/Philippino, and one Chinese patient. There were five men and five women. The ethnic backgrounds of all the Caucasian controls were European. The data for the remaining thirteen patient variables in the Asian patients and Caucasian controls are summarized in Table 1 . The data for the eight tumor variables are summarized in Table 2 .

The mean age of onset for the first BCC was significantly $(P<0.05)$ older for the Asian patients $(68.9$ years, range 43 to $85)$ than the mean age of onset of first BCC in the Caucasian controls (58.3 years, range 29 to 90 ). Also of significance was the percent of patients that had multiple (>1) lifetime BCCs, which was greater in the Caucasians than in the Asians (79.3\% versus $11.1 \% ; P<0.01)$, and the mean number of lifetime BCCs, which was also greater in the Caucasians than in the Asians (5.41 versus 1.11; $P<0.02$ ). There was a trend towards a higher percentage of Caucasians $(33.3 \%)$ that had a family history of skin cancer than the percentage of Asians with a similar history $(0 \% ; P<0.08)$. Although the $P$ value for this difference was not statistically significant, this could have been due to the small number of Asians in the study.

Most Asians in our study had a medium to dark complexion. These Asian patients were much less likely to have fair skin that Caucasian controls $(20.0 \%$ versus $62.1 \% ; P<0.04)$. The remaining patient variables were not significantly different between the Asians and Caucasians.

The percentage of BCCs in the Asians that were clinically pigmented was significantly greater than the percentage of clinically pigmented BCCs in the Caucasians $(50.0 \%$ versus $3.3 \% ; P<0.01)$. In addition, the mean tumor duration prior to treatment was longer in the Asian patients than that in the Caucasians (50.6 months versus 22.2 months; $P<0.07$ ). Although this difference did not reach statistical significance, it may be clinically important.

The biologic behavior of BCC was similar in the Asian patients and the Caucasian controls. This behavior was shown by the insignificant differences between the Asian group and the Caucasian control group with respect to BCC subtype classification, the number of Mohs stages required for BCC removal, the mean pre- and postoperative areas, and the history of prior treatment.

\section{Discussion}

In our study, we looked at Asian patients with BCC to see if the patient and tumor characteristics were different than those in Caucasians with BCC. We found equal numbers of males and females in the Asian population that developed BCC. Since we controlled for gender in the Caucasian group, there was no difference seen in the gender composition of our 
TABLE 2: Tumor variables.

\begin{tabular}{|c|c|c|c|}
\hline Tumor variable & Asians $(n=10)$ & Caucasian controls $(n=30)$ & $P$-value \\
\hline Clinical BCC pigmentation & $5(50.0 \%)$ & $1(3.3 \%)$ & $<0.01$ \\
\hline Mean duration (month) prior to treatment & $50.6 \pm 59.9$ & $22.2 \pm 33.5$ & $<0.01$ \\
\hline Tumor located on head & $10(100.0 \%)$ & $29(96.7 \%)$ & $<0.07$ \\
\hline \multicolumn{4}{|l|}{ BCC subtype } \\
\hline Nodular & $5(50.0 \%)$ & $15(50.0 \%)$ & 1 \\
\hline Infiltrative & $1(10.0 \%)$ & $5(16.5 \%)$ & 1 \\
\hline Sclerosing & $1(10.0 \%)$ & $2(6.7 \%)$ & 1 \\
\hline Other & $3(30.0 \%)$ & $8(26.4 \%)$ & 1 \\
\hline Mean number of Mohs stages & $2.33 \pm 1.0$ & $2.73 \pm 3.2$ & $<0.72$ \\
\hline Mean preoperative area $\left(\mathrm{mm}^{2}\right)$ & $114.3 \pm 228.4$ & $77.0 \pm 99.3$ & $<0.50$ \\
\hline Mean preoperative area $\left(\mathrm{mm}^{2}\right)$ & $546.3 \pm 809.6^{*}$ & $393.9 \pm 703.4^{* *}$ & $<0.60$ \\
\hline Prior treatment to the index BCC & $2(22.2 \%)^{*}$ & $9(30.0 \%)$ & 1 \\
\hline
\end{tabular}

${ }^{*} n=9$, and ${ }^{* *} n=29$ due to unavailable data.

TABLE 3: Impact of race on gender distribution of patients with cutaneous basal cell carcinoma.

\begin{tabular}{|c|c|c|c|}
\hline Study & Male : female & Age of onset & Percent of tumors in the head and neck \\
\hline \multicolumn{4}{|l|}{ Asian } \\
\hline Present study & 1 & 68.9 & 100 \\
\hline Zhang et al. [24] 1993 (Japan) & 0.94 & 58.8 & 80 \\
\hline Ikeda et al. [1] 1989 (Japan) & 1.1 & N/A & 73.6 \\
\hline Kikuchi et al. [22] 1996 (Japan) & 0.97 & 59.1 & 75.3 \\
\hline Takenouchi et al. [27] 2001 (Japan) & 0.93 & 67.1 & N/A \\
\hline Yap [32] 2010 (Malaysia) & 1.05 & 60.9 & 82.8 \\
\hline \multicolumn{4}{|l|}{ Black African } \\
\hline Mora and Burris [15] 1981 (US) & 0.82 & 59 & 76.3 \\
\hline Abreo and Sanusi [2] 1991 (US) & 0.73 & 68.5 & 88.3 \\
\hline Itayemi and Oluwasanmi [16] 1974 (Nigeria) & 0.72 & 41.1 & 57.9 \\
\hline \multicolumn{4}{|l|}{ Caucasian } \\
\hline Reizner et al. [25] 1993 (US) & 1.93 & 56.5 & 54.7 \\
\hline Green [13] 1982 (Australia) & 2.02 & N/A & 61.8 \\
\hline Czarnecki et al. [12] 1992 (Australia) & 1.95 & 51.9 & 61.7 \\
\hline Roenigk et al. [11] 1986 (US) & 1.15 & 63.8 & 58.8 \\
\hline Chuang et al. [9] 1990 (US) & 0.85 & 64.6 & 83.9 \\
\hline Swerdlow [14] 1985 (UK) & 1.2 & $\mathrm{~N} / \mathrm{A}$ & 92 \\
\hline Gallagher et al. [7] 1990 (Canada) & 1.2 & N/A & 68.8 \\
\hline Dahl et al. [8] 1992 (Sweden) & 0.97 & N/A & 60.2 \\
\hline
\end{tabular}

controls. Other studies that have been done in Asian, Black African, and Caucasian populations have varying gender results (Table 3 ). It is interesting to note that among the studies of Asians, the male to female ratio is about one (a similar ratio to that in our study), whereas in those looking at Black Africans, there appears to be a predominance of women and in studies of Caucasians, there appears to be a predominance of men with BCC. These differences may be related to cultural patterns of sun exposure (outdoor work, recreation, etc.). For instance, in the United States, men traditionally work more outdoors (e.g., fishing and farming), whereas women traditionally have indoor jobs. In Asia, perhaps women are as likely to work outdoors as men.

Sun damage to the skin is most likely the major cause of BCC. The amount of damage that occurs with sunlight exposure is related to the pigmentation within the skin. The clinically observed pigmentation within the skin is related to neither the epidermal thickness nor the number of melanocytes. Rather, it is related to the size, density, and distribution of melanosomes in keratinocytes [18]. In fair-skinned Caucasians, the melanosomes are small, nondense, and clustered within membrane-bound organelles. In Black Africans, 
large, dense melanosomes are dispersed freely within the cytoplasm. In Asians, there are small, dense melanosomes, usually clustered within membrane-bound organelles.

An increase in skin pigmentation results in reduced penetration of photons into the deeper layers of the epidermis, a finding demonstrated by Matsuoka et al. [33] who showed a reduced UVB stimulated vitamin $\mathrm{D}_{3}$ synthesis in Asians and Black Africans compared to Caucasians. By diminishing the amount of UV exposure, photon induced damage to the basal cells of the epidermis may be minimized, possibly leading to a reduced rate of malignant transformation.

Our Asian patients were found to develop their first BCC at a later age and were less likely to develop additional lesions in their lifetime than the Caucasian controls. This was true, despite having similar levels of sun, chemical, smoking, and $\mathrm{X}$-ray exposure. These findings are consistent with the idea that Asians have skin pigmentation that, on average, is more protective of the carcinogenic effect of ultraviolet light than Caucasians [34]. In our patient population, a smaller percentage of Asian patients had fair skin than Caucasians; however, no significant difference was found in the Fitzpatrick skin phototypes of the two groups. The lack of the significant difference in the Fitzpatrick classifications may be due to patient subjectivity in obtaining this variable.

Our Asian patients had a mean age (68.9 years) of onset of first BCC that was greater than the mean ages (58.8-67.1 years) of onset of first BCC in patients from most previous studies in East Asia [22, 24, 27, 32] but was similar to the results by Goh et al. [19]. The reason for this discrepancy is not clear since the previous studies did not study exposure to different risk factors. Santa Monica is at 34 degrees north latitude, a value that is comparable to many cities in southern Japan and central China. In our study, all of the Asian subjects lived the majority of their lives in Southeast/East Asia or in southern California. As a result, the intensity of sun exposure in our Asian patients is most likely similar to that of populations in other Asian BCC studies. It is possible, however, that Asians living in southern California have occupations that reduce their duration of sun exposure (more indoor jobs).

In looking at the tumors of our subjects, a significantly greater percentage of BCCs in the Asian patients were clinically pigmented than the percentage of BCCs in Caucasian controls. This greater percentage of pigmented BCCs is in agreement with Kikuchi et al., who found tumor pigmentation to be the most characteristic clinical feature of BCC in Japanese patients compared to BCC in Caucasians [22].

It has been reported that Asian patients have an incidence of BCC ranging from 16 to 20 per 100,000 [23, 26] but has been shown to be on the rise since the 1960s $[29,35]$. The incidence of BCC in Caucasians, however, has been estimated to be greater than 200 per 100,000 in females and greater than 400 per 100,000 in males [36]. As a result, physicians might be less likely to suspect a skin cancer in Asians, and Asians may be less likely to seek medical evaluation for a suspicious lesion. This lack of awareness was reflected in our data that showed tumor duration prior to treatment was greater in the Asians than in the Caucasian controls (50.6 months versus
22.2 months; $P<0.07)$. Although this difference was not statistically significant, it may be clinically important.

All Asian BCCs in our study occurred on the head and neck. In contrast, other studies from Japan and China found only $73-84 \%$ of BCCs occurring on the head and neck $[1,19$, $22,24]$. The absence of BCCs in our study that occurred on the trunk and extremities is most likely due to the difference in referral patterns. BCCs referred to Mohs micrographic surgery are generally located on the head and neck.

We found that all Asian patients had a negative history of non-BCC skin cancer and a negative family history of skin cancer. Most likely this is due to the previously discussed lower incidence of skin cancer in this population.

In conclusion, BCC is a relatively uncommon skin cancer in Asians. When it does occur, it is no more aggressive than BCC in Caucasians. Physicians should be aware that BCC can occur in Asians and that early detection and treatment will result in the highest cure rate and the best cosmetic outcome.

\section{Acknowledgment}

There were no funding sources that supported this work. The authors have no conflicts of interest to disclose. This paper has not been presented previously nor is it scheduled for presentation.

\section{References}

[1] S. Ikeda, Y. Kiyohara, and H. Mizutani, "Comparative aspects of melanoma and non-melanoma skin cancers in Japan," Journal of Investigative Dermatology, vol. 92, no. 5, pp. 204209, 1989.

[2] F. Abreo and I. D. Sanusi, "Basal cell carcinoma in North American blacks: clinical and histopathologic study of 26 patients," Journal of the American Academy of Dermatology, vol. 25, no. 6, pp. 1005-1011, 1991.

[3] M. A. Gohara, "Skin cancer in skins of color," Journal of Drugs in Dermatology, vol. 7, no. 5, pp. 441-445, 2008.

[4] S. J. Miller, "Biology of basal cell carcinoma, I," Journal of the American Academy of Dermatology, vol. 24, no. 2, pp. 1-13, 1991.

[5] A. J. J. Emmett, "Surgical analysis and biological behaviour of 2277 basal cell carcinomas," Australian and New Zealand Journal of Surgery, vol. 60, no. 11, pp. 855-863, 1990.

[6] M. Sexton, D. B. Jones, and M. E. Maloney, "Histologic pattern analysis of basal cell carcinoma: study of a series of 1039 consecutive neoplasms," Journal of the American Academy of Dermatology, vol. 23, no. 6, pp. 1118-1126, 1990.

[7] R. P. Gallagher, B. Ma, D. I. McLean et al., "Trends in basal cell carcinoma, squamous cell carcinoma, and melanoma of the skin from 1973 through 1987," Journal of the American Academy of Dermatology, vol. 23, no. 3, pp. 413-421, 1990.

[8] E. Dahl, M. Aberg, A. Rausing, and E. L. Rausing, "Basal cell carcinoma," Cancer, vol. 70, pp. 104-108, 1992.

[9] T. Y. Chuang, A. Popescu, W. P. D. Su, and C. G. Chute, "Basal cell carcinoma. A population-based incidence study in Rochester, Minnesota," Journal of the American Academy of Dermatology, vol. 22, no. 3, pp. 413-417, 1990.

[10] M. E. Maloney, D. B. Jones, and F. M. Sexton, "Pigmented basal cell carcinoma: investigation of 70 cases," Journal of 
the American Academy of Dermatology, vol. 27, no. 1, pp. 7478, 1992.

[11] R. K. Roenigk, J. L. Ratz, P. L. Bailin, and R. G. Wheeland, "Trends in the presentation and treatment of basal cell carcinomas," Journal of Dermatologic Surgery and Oncology, vol. 12, no. 8, pp. 860-865, 1986.

[12] D. Czarnecki, N. Collins, C. Meehan, T. O’Brien, S. Leahy, and C. Nash, "Basal-cell carcinoma in temperate and tropical Australia," International Journal of Cancer, vol. 50, no. 6, pp. 874-875, 1992.

[13] A. J. Green, "Basal cell carcinoma in Queensland: a new trend," Australian and New Zealand Journal of Surgery, vol. 52, no. 1, pp. 63-65, 1982.

[14] A. J. Swerdlow, "Seasonality of presentation of cutaneous melanoma, squamous cell cancer and basal cell cancer in the Oxford region," British Journal of Cancer, vol. 52, no. 6, pp. 893-900, 1985.

[15] R. G. Mora and R. Burris, "Cancer of the skin in blacks: a review of 128 patients with basal-cell carcinoma," Cancer, vol. 47, no. 6, pp. 1436-1438, 1981.

[16] S. O. Itayemi and J. O. Oluwasanmi, "Basal cell carcinoma in Negro Nigerians," Tropical and Geographical Medicine, vol. 26, no. 4, pp. 425-428, 1974.

[17] D. A. Weigand, C. Haygood, and J. R. Gaylor, "Cell layers and density of Negro and Caucasian stratum corneum," Journal of Investigative Dermatology, vol. 62, no. 6, pp. 563-568, 1974.

[18] R. A. Sturm, N. F. Box, and M. Ramsay, "Human pigmentation genetics: the difference is only skin deep," BioEssays, vol. 20, no. 9, pp. 712-721, 1998.

[19] B. K. Goh, P. Ang, Y. J. Wu, and C. L. Goh, "Characteristics of basal cell carcinoma amongst Asians in Singapore and a comparison between completely and incompletely excised tumors," International Journal of Dermatology, vol. 45, no. 5, pp. 561-564, 2006.

[20] T. Ono, M. Kitoh, and N. Kuriya, "Characterization of basal cell epithelioma in the Japanese," Journal of Dermatology, vol. 9, no. 4, pp. 291-300, 1982.

[21] M. Tada and Y. Miki, "Malignant skin tumors among dermatology patients in university hospitals of Japan. A statistical survey 1971-1975," Journal of Dermatology, vol. 11, no. 4, pp. 313-321, 1984.

[22] A. Kikuchi, H. Shimizu, and T. Nishikawa, "Clinical and histopathological characteristics of basal cell carcinoma in Japanese patients," Archives of Dermatology, vol. 132, no. 3, pp. 320-324, 1996.

[23] Y. Miki, "Basal cell epithelioma among Japanese," Australasian Journal of Dermatology, vol. 9, no. 4, pp. 304-313, 1968.

[24] B. Zhang, N. Wang, and W. He, "Clinicopathologic analysis of 60 cases of basal cell carcinoma," Chinese Medical Sciences Journal, vol. 8, no. 2, pp. 121-122, 1993.

[25] G. T. Reizner, T. Y. Chuang, D. J. Elpern, J. L. Stone, and E. R. Farmer, "Basal cell carcinoma in Kauai, Hawaii: the highest documented incidence in the United States," Journal of the American Academy of Dermatology, vol. 29, no. 2, pp. 184-189, 1993.

[26] M. Ichihashi, K. Naruse, S. Harada et al., "Trends in nonmelanoma skin cancer in Japan," Recent Results in Cancer Research, vol. 139, pp. 263-273, 1995.

[27] T. Takenouchi, S. Nomoto, and M. Ito, "Factors influencing the linear depth of invasion of primary basal cell carcinoma," Dermatologic Surgery, vol. 27, no. 4, pp. 393-396, 2001.

[28] G. K. Kim, J. Q. del Rosso, and S. Bellew, "Skin cancer in asians part 1: nonmelanoma skin cancer," Journal of Clinical and Aesthetic Dermatology, vol. 2, no. 8, pp. 39-42, 2009.
[29] D. Koh, H. Wang, J. Lee, K. S. Chia, H. P. Lee, and C. L. Goh, "Basal cell carcinoma, squamous cell carcinoma and melanoma of the skin: analysis of the Singapore Cancer Registry data 1968-1997," British Journal of Dermatology, vol. 148, no. 6, pp. 1161-1166, 2003.

[30] H. R. Jin, J. Y. Lee, W. L. Dong et al., "Primary facial skin cancer: clinical characteristics and surgical outcome in Chungbuk Province, Korea," Journal of Korean Medical Science, vol. 20, no. 2, pp. 279-282, 2005.

[31] M. A. Pathak and P. Nghiem, "Chapter 138: acute and chronic effects of the sun," in Fitzpatrick's Dermatology in General Medicine, I. M. Freedberg, A. Z. Eisen, K. Wolff, K. F. Austen, L. A. Goldsmith, and S. Katz, Eds., vol. 1, pp. 1598-1604, McGraw-Hill, Health Professions Division, New York, NY, USA, 5th edition, 2000.

[32] F. B. B. Yap, "Clinical characteristics of basal cell carcinoma in a tertiary hospital in Sarawak, Malaysia," International Journal of Dermatology, vol. 49, no. 2, pp. 176-179, 2010.

[33] L. Y. Matsuoka, J. Wortsman, J. G. Haddad, P. Kolm, and B. W. Hollis, "Racial pigmentation and the cutaneous synthesis of vitamin D," Archives of Dermatology, vol. 127, no. 4, pp. 536538, 1991.

[34] N. G. Jablonski and G. Chaplin, "The evolution of human skin coloration," Journal of Human Evolution, vol. 39, no. 1, pp. 57106, 2000.

[35] J. Sng, D. Koh, W. C. Siong, and T. B. Choo, "Skin cancer trends among Asians living in Singapore from 1968 to 2006," Journal of the American Academy of Dermatology, vol. 61, no. 3, pp. 426-432, 2009.

[36] D. L. Miller and M. A. Weinstock, "Nonmelanoma skin cancer in the United States: incidence," Journal of the American Academy of Dermatology, vol. 30, no. 5, pp. 774-778, 1994. 


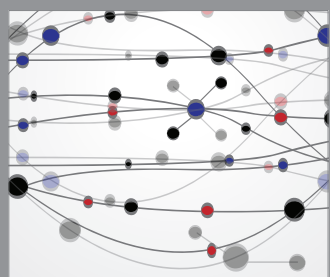

The Scientific World Journal
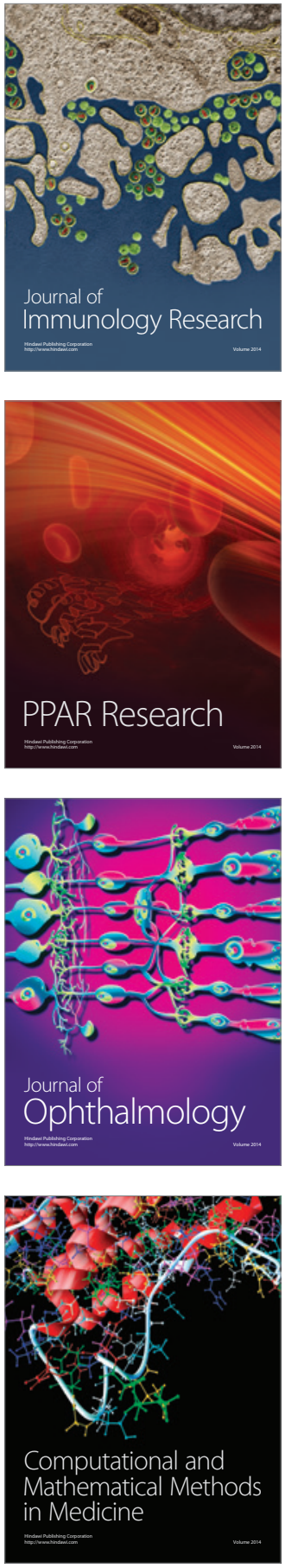

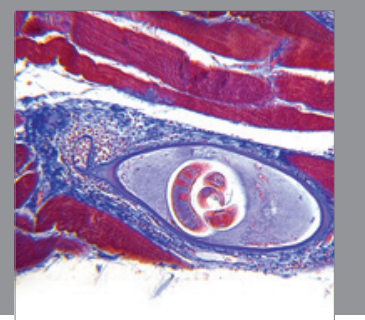

Gastroenterology

Research and Practice
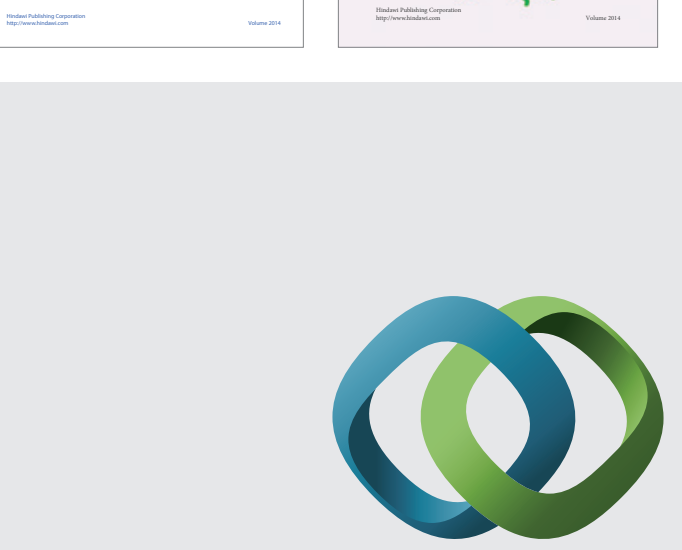

\section{Hindawi}

Submit your manuscripts at

http://www.hindawi.com
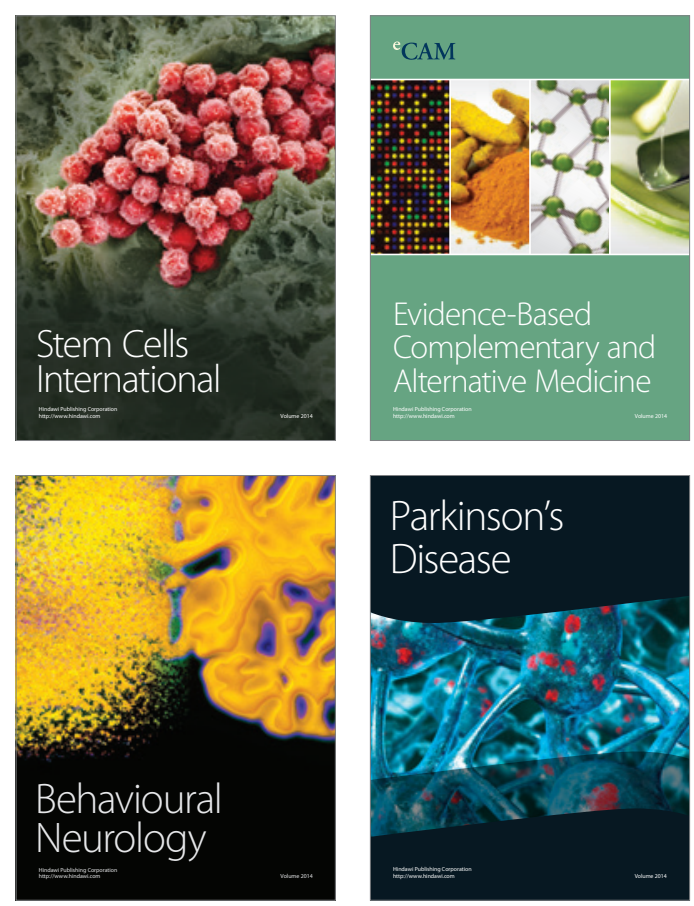

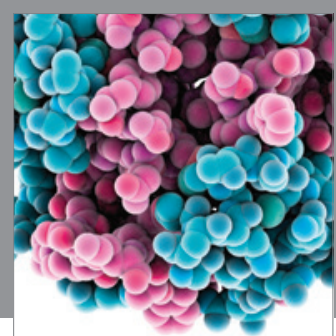

Journal of
Diabetes Research

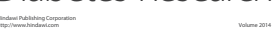

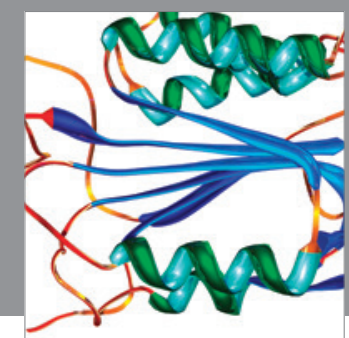

Disease Markers
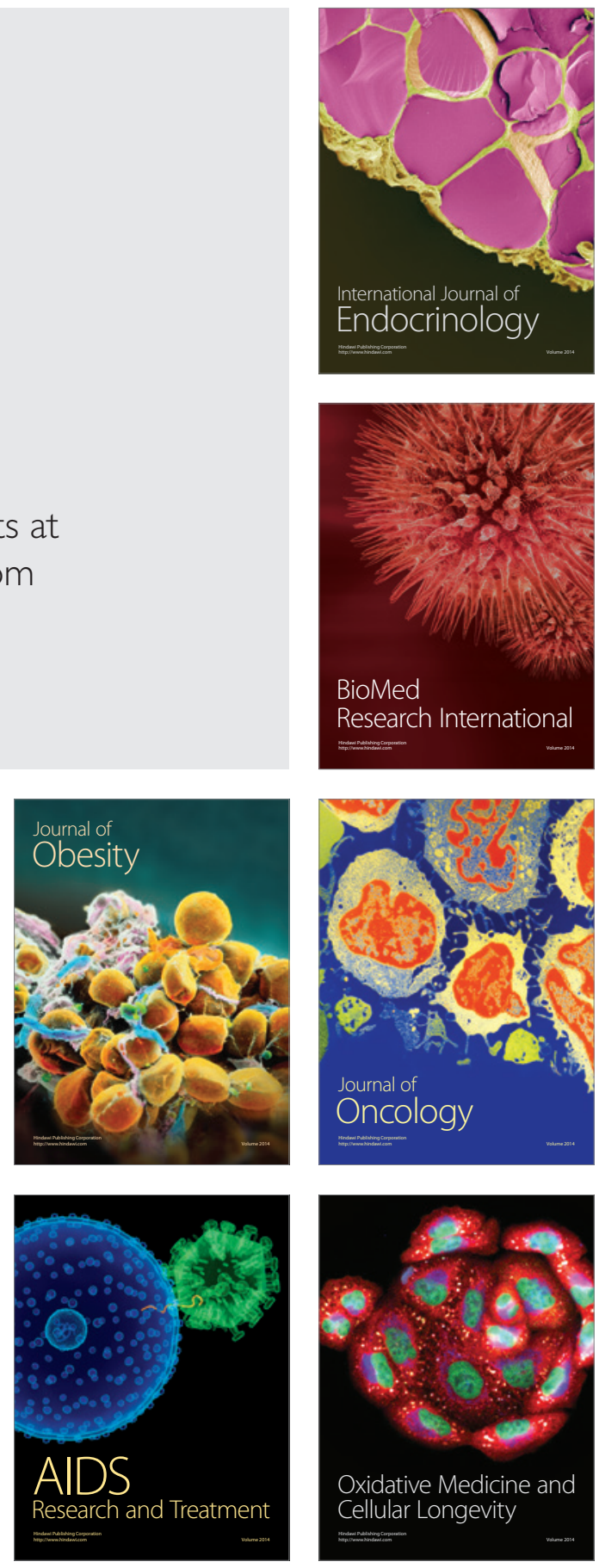